\title{
Enantioselective Synthesis and Structure Revision of Solandelactone E
}

\author{
Jennifer E. Davoren and Stephen F. Martin \\ Department of Chemistry and Biochemistry, The University of Texas, Austin, Texas.
}

The solandelactones comprise a novel group of oxylipins that were isolated from the hydroid Solanderia secunda off the Korean coast in $1996 .{ }^{1}$ The solandelactones contain cyclopropane and eight-membered lactone rings together with variable degrees of unsaturation at $\mathrm{C}(4)$ and $\mathrm{C}(19)$. Depending upon the absolute stereochemistry at C(11), they are categorized into two series, representative members of which include solandelactones $\mathrm{F}$ and $\mathrm{E}$ that were originally assigned the structures $\mathbf{1}$ and $\mathbf{2}$, respectively. Owing to their limited availability from natural sources, these oxylipins have not been thoroughly tested, but some exhibit promising biological activity as inhibitors of farnesyl transferase.

None of the solandelactones have been synthesized, but a number of related oxylipins, including constanolactones $\mathrm{A}$ and $\mathrm{B}^{2}$ and several halicholactones, ${ }^{3}$ have succumbed to total synthesis. Arguably, tactics that were employed in these successful ventures might be applied to the solandelactones; however, none of those approaches provide adequate control of the stereochemistry at the five stereogenic centers resident in the oxylipins, especially at the cyclopropyl carbinyl stereocenters.

In developing a unified strategy for the synthesis of the solandelactones, we sought to address deficiencies in the prior art and thus formulated the plan outlined in retrosynthetic format in Scheme 1 . The stereocenter at C(14) of $\mathbf{1}$ would be established by first inverting the stereochemistry at $\mathrm{C}(12)$ in diol $\mathbf{3}$ followed by a 1,3-transposition of the allylic hydroxyl group. Conversely, the synthesis of 2 would require direct 1,3-transposition of the $\mathrm{C}(12)$ hydroxy group in $\mathbf{4}$. The $\mathrm{C}(1)-\mathrm{C}(5)$ and $\mathrm{C}(16)-\mathrm{C}(22)$ segments in $\mathbf{3}$ and $\mathbf{4}$ would be appended by epoxide openings and $\mathrm{S}_{\mathrm{N}} 2$ reactions, whereas the absolute and relative stereochemistry of the diol arrays in $\mathbf{3}$ and $\mathbf{4}$ would be created via Sharpless asymmetric dihydroxylations of the cyclopropyl diene $\mathbf{5}$. This diene, which would be accessed from the known ester $\mathbf{6}^{4}$ by cyclopropanation and chain elongation, would serve as the pivotal intermediate for the syntheses of both series of solandelactones epimeric at $\mathrm{C}(11)$.

The first stage of the synthetic plan was initiated with the olefination of commercially available D-glyceraldehyde acetonide (7) with trans-triethyl phosphonocrotonate to give $\mathbf{6}$ as a mixture (10:1) of olefin isomers that was treated with $\mathrm{Zn}\left(\mathrm{CH}_{2} \mathrm{I}\right)_{2}$ at $65^{\circ} \mathrm{C}$ in a sealed tube to furnish cyclopropane $\mathbf{8}$ (Scheme 2). ${ }^{5}$ The stereochemical assignment of $\mathbf{8}$ was secured by obtaining the xray structure of the derived carbamate $\mathbf{1 2}$. Sequential hydride reduction of the ester group in 8 followed by TPAP6 ${ }^{6}$ idation of the intermediate alcohol and olefination of the resultant aldehyde led to the diene 9 as a 10:1 mixture of $E / Z$ olefin isomers.

E-mail:sfmartin@mail.utexas.edu.

supporting Information Available. Experimental procedures for 9, 16, 1; full characterization and copies of ${ }^{1} \mathrm{H}$ NMR spectra for all new compounds; and a tabular comparison of ${ }^{1} \mathrm{H}$ and ${ }^{13} \mathrm{C}$ NMR data for synthetic and natural 1 . This material is available free of charge via the Internet at http://pubs.acs.org. 
When 9 was treated with AD-mix $\beta$, diol 10 was isolated in $80 \%$ yield as a single diastereomer, 7 whereas reaction of $\mathbf{9}$ with AD-mix $\alpha$ provided diastereomeric diols $\mathbf{1 1}$ and $\mathbf{1 0}$ in $78 \%$ yield as an inseparable mixture (3:1). The stereochemistry of $\mathbf{1 0}$ and $\mathbf{1 1}$ were assigned to be $11(R) /$ $12(R)$ and $11(S) / 12(S)$, respectively, by applying the Sharpless model. ${ }^{8}$ Inasmuch as $\mathbf{1 0}$ and 11 might be separately transformed into the corresponding diols $\mathbf{3}$ and $\mathbf{4}$, the asymmetric dihydroxylation of 9 using either AD-mix $\beta$ or AD-mix $\alpha$ enabled us in principle to prepare both $\mathrm{C}(11)$ epimeric series of solandelactones from a common intermediate.

Because 10 was accessible with higher efficiency than 11, we elected to transform it into a natural solandelactone. The next phase of the synthesis thus required elaboration of $\mathbf{1 0}$ by introducing the remaining carbon atoms of the $\mathrm{C}(1)-\mathrm{C}(5)$ and $\mathrm{C}(16)-\mathrm{C}(22)$ subunits. In the event, diol 10 was protected as its bis-TBS ether, and the ester function was transformed in two steps to furnish the allylic bromide 13 (Scheme 3). 9 Treatment of $\mathbf{1 3}$ with lithiated 1heptyne in the presence of a catalytic amount of $\mathrm{Cu}(\mathrm{I})$ provided the enyne 14 as the sole product. Selective removal of the acetonide moiety in the presence of the somewhat acid-labile TBSprotecting groups required some experimentation, but we eventually found that hydrolysis of 14 using a two-phase solution of $\mathrm{CH}_{2} \mathrm{Cl}_{2}$ and aqueous TFA gave a diol, ${ }^{10}$ which was converted into the corresponding epoxide $\mathbf{1 5}$ in a single step employing a Fraser-Reid protocol. ${ }^{11}$ This epoxide was very acid sensitive and underwent facile rearrangement to a $\beta$-cyclopropyl aldehyde upon purification by flash silica gel chromatography. ${ }^{12}$

When 15 was treated with the anion of THP-pentynol according to the Yamaguchi procedure, 13 ring opening of the epoxide ensued to give an alcohol that was acetylated under standard conditions to give 16. The tetrahydropyranyl group on $\mathbf{1 6}$ was selectively cleaved using $i-\mathrm{PrOH}$ as solvent, whereas use of more conventional solvents such as $\mathrm{H}_{2} \mathrm{O}, \mathrm{MeOH}$ and $\mathrm{EtOH}$ led to significant loss of the TBS protecting groups. Catalytic semi-hydrogenation using Lindlar's catalyst then delivered triene $\mathbf{1 7}$, which incorporates the complete carbon skeleton of the solandelactones.

It then remained to form the eight-membered lactone ring and induce the 1,3-transposition of the $\mathrm{C}(12)$ allylic alcohol. Toward this end, a two-stage oxidation of the primary alcohol in 17, followed by saponification of the C(7) acetate gave the hydroxy acid $\mathbf{1 8}$ (Scheme 4). Cyclization of 18 to an eight-membered lactone under the conditions developed by Yamaguchi ${ }^{14}$ and subsequent TBAF mediated deprotection of both TBS ethers proceeded uneventfully to give diol 19. The stage was thus set for the transposition of the allylic alcohol array at $\mathrm{C}(12)-\mathrm{C} 14)$. Despite the apparent simplicity of this transformation, it proved to be much more difficult to induce than we had anticipated. Ultimately, we discovered that reaction of 19 with onitrophenylselenocyanate and tri- $n$-butylphosphine led to activation and substitution with inversion of the less-hindered alcohol at $\mathrm{C}(12)$ to give a selenide that was converted into 1 in modest overall yield via oxidation and [2,3]-sigmatropic rearrangement of the intermediate allylic selenoxide. 15

Based upon the structures assigned to the solandelactones in the literature, ${ }^{1}$ we believed we had thus completed the total synthesis of solandelactone F. However, when we compared our spectral data with those in the literature, we realized we had not. The structural assignment of synthetic 1 seemed secure based upon the x-ray analysis of 12, the known stereochemical preference for asymmetric dihydroxylations, 8 and the preferred stereoselectivity of [2,3]sigmatropic rearrangements. ${ }^{16}$ However, the ${ }^{1} \mathrm{H}$ and ${ }^{13} \mathrm{C}$ NMR data for synthetic 1 nicely matched those given for solandelactone $\mathrm{E}$, which had been incorrectly depicted as the $\mathrm{C}(11)$ epimer 2.17

In summary, we designed a novel and convergent strategy for oxylipin synthesis that culminated in the first total synthesis of solandelactone E (1) and a revision of the original 
structural assignments of the $\mathrm{C}(11)$-epimeric solandelactones. The synthesis, which provides the first effective solution to the numerous stereochemical challenges posed by the oxylipin class of natural products, features an acetal directed cyclopropanation, an asymmetric dihydroxylation, and a 1,3-chirality transfer.

\section{Supplementary Material}

Refer to Web version on PubMed Central for supplementary material.

\section{Acknowledgment}

We thank the National Institutes of Health (GM 31077), the Robert A. Welch Foundation, Pfizer, Inc., and Merck Research Laboratories for generous support of this research. We are also grateful to Dr. Christian Harcken (BoehringerIngelheim Pharmaceuticals, Inc.) for helpful discussions and Prof. Jongheon Shin (College of Pharmacy, Seoul National University) for providing spectral data for solandelactones $\mathrm{E}$ and $\mathrm{F}$.

\section{References}

1. Seo Y, Cho KW, Rho J-R, Shin J, Kwon B-M, Bok S-H, Song J-I. Tetrahedron 1996;52:10583.

2 (a). For recent examples see:Pietruszka J, Wilhelm T. Synlett 2003:1698. (b) Yu J, Lai J-Y, Ye J, Balu N, Reddy LM, Duan W, Fogel ER, Capdevila JH, Falck JR. Tetrahedron Lett 2002;43:3939. (c) Silva CB-D, Benkouider A, Pale P. Tetrahedron Lett 2000;41:3077.

3 (a). For recent examples see:Takahashi T, Watanabe H, Kitahara T. Heterocycles 2002;58:99. (b) Baba Y, Saha G, Nakao S, Iwata C, Tanaka T, Ibuka T, Ohishi H, Takemoto Y. J. Org. Chem 2001;66:81. [PubMed: 11429933] (c) Critcher DJ, Connolly S, Wills M. J. Org. Chem 1997;62:6638.

4. Li S-K, Xu R, Xiao X-S, Bai D-L. Chinese J. Chem 2000;18:910.

5. For a related example see:Morikawa T, Sasaki H, Hanai R, Shibuya A, Taguchi T. J. Org. Chem 1994;59:97.

6. Ley SV, Norman J, Griffith WP, Marsden SP. Synthesis 1994:639.

7. Xu D, Crispino GA, Sharpless KB. J. Am. Chem. Soc 1992;114:7570.

8 (a). Norrby P-O, Kolb HC, Sharpless KB. J. Am. Chem. Soc 1994;116:8470. (b) Kolb HC, Andersson PG, Sharpless KB. J. Am. Chem. Soc 1994;116:1278.

9. Appel R. Angew. Chem. Int. Ed 1975;87:801.

10. Smith AB III, Doughty VA, Sfouggatakis C, Bennett CS, Koyanagi J, Takeuchi M. Org. Lett 2002;4:783. [PubMed: 11869127]

11. Hicks DR, Fraser-Reid B. Synthesis 1974:203.

12. Meinwald J, Labana SS, Labana LL, Wahl GH Jr. Tetrahedron Lett 1965:1789.

13. Yamaguchi M, Hirao I. Tetrahedron Lett 1983;24:391.

14. Inanaga J, Hirata K, Saeki H, Katsuki T, Yamaguchi M. Bull. Chem. Soc. Jpn 1979;52:1989.

15. As noted by a referee, this transformation might also proceed via epoxide intermediates to furnish diastereoisomeric allylic selenides that would deliver solandelactone $F(2)$ or the $C(14)$ epimer of 1 upon oxidation and [2,3]-sigmatropic rearrangement. That this possibility was not the source of the discrepancy in structure assignments was established by an independent synthesis of $\mathbf{1}$ from $\mathbf{1 9}$ in lower overall yield by a five-step reaction sequence in which the $\mathrm{C}(11)$ hydroxyl group was selectively protected as a PMB ether: (a) $p-\mathrm{MeOC}_{6} \mathrm{H}_{4}(\mathrm{OMe})_{2}$, TsOH, DMF, rt, $80 \%$. (b) $\mathrm{NaBH}_{3} \mathrm{CN}$, TFA, THF, $0{ }^{\circ} \mathrm{C}, 50 \%$. (c) $o-\mathrm{NO}_{2} \mathrm{PhSeCN}, \mathrm{Bu}_{3} \mathrm{P}$, THF, rt; $\mathrm{H}_{2} \mathrm{O}_{2}$, pyridine, $\mathrm{CH}_{2} \mathrm{Cl}_{2}, \mathrm{rt}, 56 \%$. (d) DDQ, $\mathrm{H}_{2} \mathrm{O}, \mathrm{CH}_{2} \mathrm{Cl}_{2}, \mathrm{rt}, 72 \%$.

16. Nishibayashi Y, Uemura S. Top. Curr. Chem 2000;208:2015.

17. In corresponding with Professor Shin, it became apparent that there was a clerical error in correlating the names of the $\mathrm{C}(11)$-epimeric solandelactones with their respective structures in reference 1 . He concurs that those assignments should be revised in accord with the present findings. 


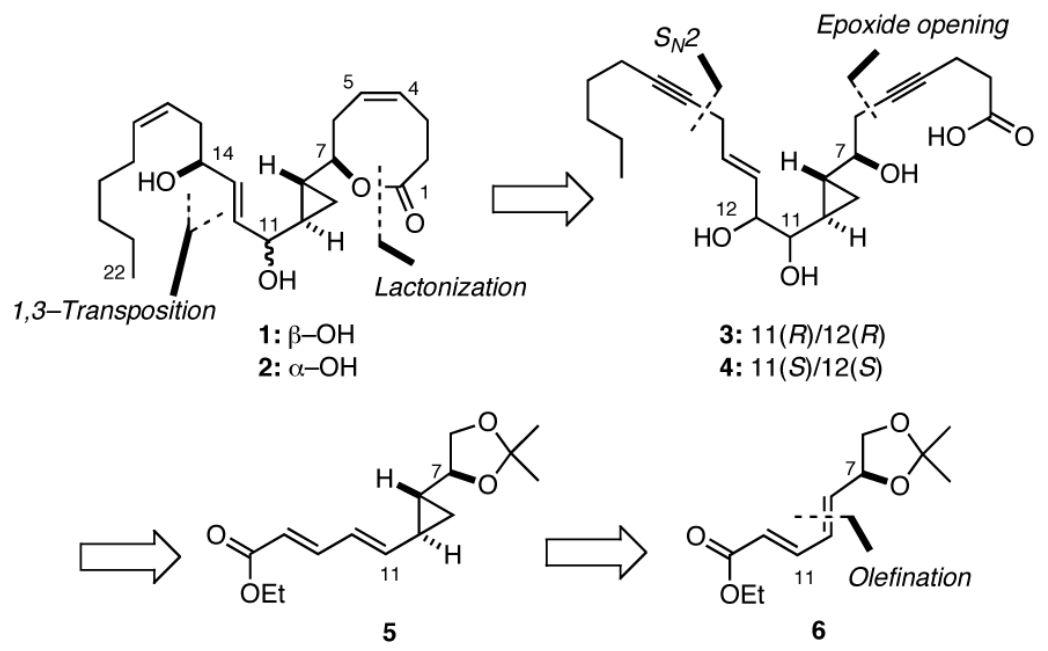

Scheme 1. 


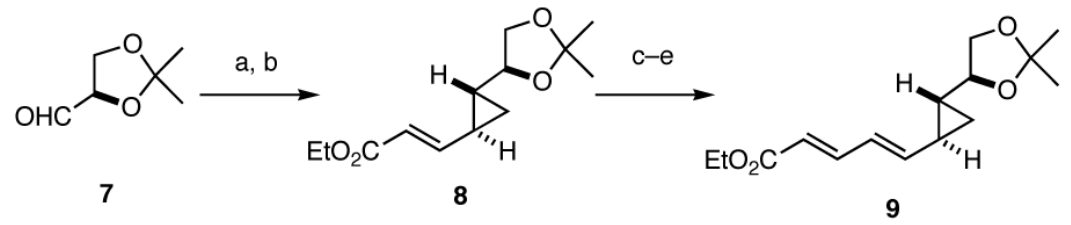

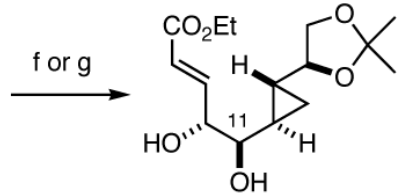

10<smiles>CCOC(=O)C=CC1COC(C)(C)O1</smiles>

11

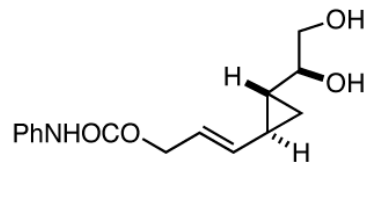

12

Scheme 2a.

$a$ Reaction conditions: (a) trans-(EtO) ${ }_{2} \mathrm{P}(\mathrm{O}) \mathrm{CH}_{2} \mathrm{CHCHCO}_{2} \mathrm{Et}, \mathrm{LDA}, \mathrm{THF}, 0{ }^{\circ} \mathrm{C}, 89 \%, 10: 1$ EE/EZ; (b) $\mathrm{Et}_{2} \mathrm{Zn}, \mathrm{CH}_{2} \mathrm{I}_{2}, \mathrm{CH}_{2} \mathrm{Cl}_{2}, 65^{\circ} \mathrm{C}, 72 \%$; (c) DIBAL, $\mathrm{CH}_{2} \mathrm{Cl}_{2},-78^{\circ} \mathrm{C}, 88 \%$; (d) TPAP, $\mathrm{NMO}, \mathrm{CH}_{2} \mathrm{Cl}_{2}$, rt, 98\%; (e) (EtO) ${ }_{2} \mathrm{P}(\mathrm{O}) \mathrm{CH}_{2} \mathrm{CO}_{2} \mathrm{Et}, \mathrm{NaH}, \mathrm{THF}, 0{ }^{\circ} \mathrm{C}, 89 \%, 10: 1 \mathrm{E} / \mathrm{Z}$; (f) $\mathrm{K}_{3} \mathrm{Fe}$ $(\mathrm{CN})_{6}, \mathrm{~K}_{2} \mathrm{CO}_{3}, \mathrm{~K}_{2} \mathrm{OsO}_{2}(\mathrm{OH})_{4}$, (DHQD) ${ }_{2} \mathrm{PHAL}, \mathrm{CH}_{3} \mathrm{SO}_{2} \mathrm{NH}_{2}, t-\mathrm{BuOH} / \mathrm{H}_{2} \mathrm{O}, \mathrm{rt}, 80 \%$, > 20:1 $\mathrm{dr} ;(\mathrm{g}) \mathrm{K}_{3} \mathrm{Fe}(\mathrm{CN})_{6}, \mathrm{~K}_{2} \mathrm{CO}_{3}, \mathrm{~K}_{2} \mathrm{OsO}_{2}(\mathrm{OH})_{4}$, (DHQ) $)_{2} \mathrm{PHAL}, \mathrm{CH}_{3} \mathrm{SO}_{2} \mathrm{NH}_{2}, t-\mathrm{BuOH} / \mathrm{H}_{2} \mathrm{O}$, rt, $78 \%, 3: 1 \mathrm{dr}$. 


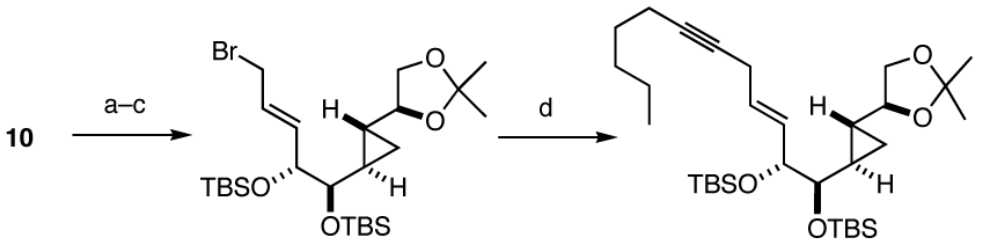

13

14

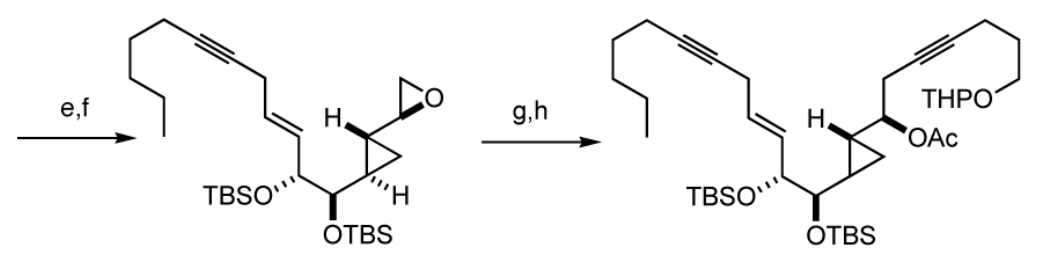

15

16

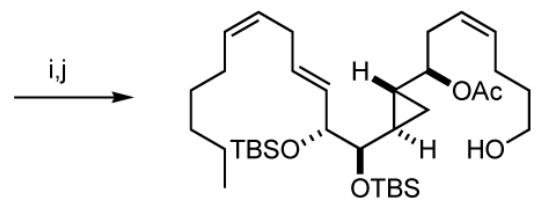

17

Scheme 3a.

$a$ Reaction conditions: (a) TBSCl, imidazole, DMF, rt, 99\%; (b) DIBAL-H, $\mathrm{CH}_{2} \mathrm{Cl}_{2},-78{ }^{\circ} \mathrm{C}$, 95\%; (c) $\mathrm{CBr}_{4}, \mathrm{PPh}_{3}, \mathrm{CH}_{2} \mathrm{Cl}_{2}, \mathrm{rt}, 96 \%$; (d) $n$-BuLi, 1-heptyne, $\mathrm{CuBr} \bullet \mathrm{SMe}_{2},-78^{\circ} \mathrm{C}$ to rt, $95 \%$; (e) TFA, $\mathrm{H}_{2} \mathrm{O}, \mathrm{CH}_{2} \mathrm{Cl}_{2}, \mathrm{rt}, 82 \%$; (f) $\mathrm{NaH}, 1$-tosylimidazole, THF, $0{ }^{\circ} \mathrm{C}, \sim 100 \%$; (g) THPO $\left(\mathrm{CH}_{2}\right)_{3} \mathrm{C} \equiv \mathrm{CH}, n-\mathrm{BuLi}, \mathrm{BF}_{3} \mathrm{OEt}_{2}, \mathrm{THF},-78{ }^{\circ} \mathrm{C}, 45 \%$; (h) $\mathrm{Ac}_{2} \mathrm{O}, \mathrm{DMAP}, \mathrm{Et}_{3} \mathrm{~N}, \mathrm{CH}_{2} \mathrm{Cl}_{2}, \mathrm{rt}$, 92\%; (i) $p$-TsOH, $i$-PrOH, rt, 87\%; (j) $\mathrm{H}_{2}$, Lindlar catalyst, quinoline, $\mathrm{MeOH}, \mathrm{rt}, 94 \%$. 


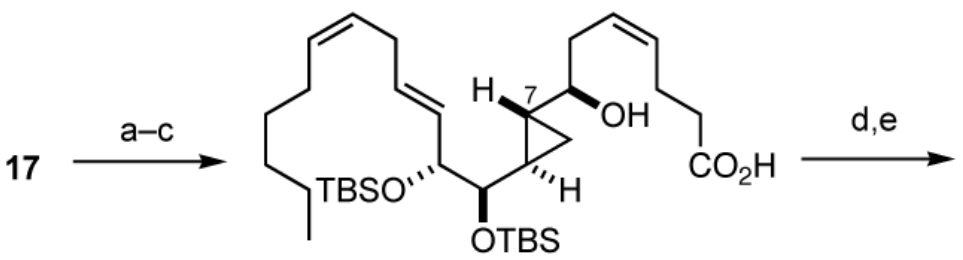

18

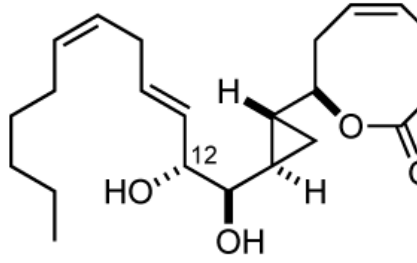

19<smiles>CCCCC/C=C\C[14C](O)/C=C/C(O)[C@H]1C[C@H]1C1C/C=C\CCC(=O)O1</smiles>

1

Scheme 4a.

$a$ Reaction conditions: (a) $\mathrm{SO}_{3}$.Pyridine, $\mathrm{Et}_{3} \mathrm{~N}, \mathrm{DMSO}, \mathrm{rt}, \mathrm{CH}_{2} \mathrm{Cl}_{2}, 85 \%$; (b) $\mathrm{NaClO}_{2}$, $\mathrm{NaH}_{2} \mathrm{PO}_{4}$, 2-methyl-2-butene, $t$-BuOH, $\mathrm{H}_{2} \mathrm{O}$, rt, 90\%; (c) $\mathrm{K}_{2} \mathrm{CO}_{3}, \mathrm{MeOH}$, rt, 95\%; (d) 2,4,6trichlorobenzoyl chloride, Et ${ }_{3} \mathrm{~N}$, DMAP, PhMe, $\Delta, 81 \%$; (e) TBAF, THF, rt, 72\%; (f) $o$ $\mathrm{NO}_{2} \mathrm{PhSeCN}, \mathrm{Bu}_{3} \mathrm{P}$, THF, rt; (g) $\mathrm{H}_{2} \mathrm{O}_{2}$, pyridine, $\mathrm{CH}_{2} \mathrm{Cl}_{2}, \mathrm{rt}, 20 \%$ (2 steps). 